\title{
Erratum to: Abnormal Myocardial Strain Indices in Children Receiving Anthracycline Chemotherapy
}

\author{
Ricardo H. Pignatelli ${ }^{1} \cdot$ Payam Ghazi $^{2} \cdot$ S. Chandra-Bose Reddy ${ }^{1}$. \\ Patrick Thompson $^{2}$ Q Qiqiong Cui ${ }^{1} \cdot$ Jacqueline Castro $^{1} \cdot$ Mehmet F. Okcu $^{2}$ • \\ John Lynn Jefferies ${ }^{3}$
}

Published online: 28 August 2015

(C) Springer Science+Business Media New York 2015

\section{Erratum to: Pediatr Cardiol \\ DOI 10.1007/s00246-015-1203-8}

The original version of this article unfortunately contained a mistake in the author's group. The given name of Payam Ghazi was misspelled and the first and middle names of John Lynn Jefferies were interchanged. The two co-author names are corrected with this erratum.

The online version of the original article can be found under doi:10.1007/s00246-015-1203-8.

Ricardo H. Pignatelli

cardop@bcm.tmc.edu

1 Division of Pediatric Cardiology, Texas Children's Hospital, MC-19345 C, 19th Floor West Tower, 6621 Fannin Street,

Houston, TX 77030, USA

2 Pediatric Hematology and Oncology, Texas Children's, Hospital, Houston, TX, USA

3 Division of Pediatrics Cardiology, Cincinnati Children's, Hospital, Cincinnati, OH, USA 